\title{
MÍDIA E OPINIÃO PÚBLICA
}

\section{Giovana Olicshevis*}

RESUMO: "Para a maioria das pessoas, só existem dois lugares no mundo: o lugar onde elas vivem e a televisão". Esta frase da personagem de Ruído Branco, do romance de Don DeLillo ${ }^{1}$ exemplifica bem a atual influência da televisão e dos meios de comunicação em geral no mundo moderno. O impacto da mídia advém de tempos. Seja com o surgimento da imprensa diária no século XVII, com a chegada do rádio no Brasil em 1935 ou com a TV na década de 1950. O consumo e a quantidade de informação aumentou consideravelmente no século XXI. Atualmente se está exposto a todo tipo de informação, mas principalmente informações específicas filtradas pelos veículos de comunicação. Publica-se o que mais interessa ao público. Mas quem define o que é de interesse público? Sabe-se que a mídia é a responsável pela produção de uma agenda pública, o que os estudiosos da área denominam agenda setting. Se a mídia tem a capacidade formular questões públicas, os lideres e formadores de opinião têm preocupação de fornecer uma resposta a essas questões. É nesse contexto que acontece a "formação da opinião pública".

PALAVRAS-CHAVE: Mídia; Público; Opinião pública.

\section{Conceito de opinião pública}

Pensar em opinião pública nos remete à idéia de grupo, de público, de opinião e de indivíduo. Segundo Sarah Chucid da Via, a "opinião é conjunto de crenças a respeito de temas controvertidos ou relacionados com interpretação valorativa ou o significado moral de certos fatos". ${ }^{2}$

* Giovana Olischevis é estudante do $7^{\circ}$ período do curso de Comunicação Social Habilitação em Jornalismo da Universidade Federal do Paraná (UFPR).

${ }^{1}$ DELILLO, D. Ruído Branco. São Paulo: Companhia das Letras, 1987.

${ }^{2}$ DA VIÁ, Sarah Chucid. Opinião pública: técnica de formação e problemas de controle. São Paulo: Loyola, 1983, p. 58. 
Já Monique Augras explica que "a opinião é um fenômeno social. Existe apenas em relação a um grupo, é um dos modos de expressão desse grupo e difunde-se utilizando as redes de comunicação do grupo". ${ }^{3}$

Pode-se dizer que a opinião tem sua origem nos grupos e esses grupos transformam-se em públicos quando se organizam em torno dos temas de discussão e de interesse público. Assim, eles discutem e procuram uma atitude comum. Segundo Sarah Chucid da Via, atitude é "uma tendência para atuar, agir. Relaciona-se com os hábitos, com os comportamentos e transforma-se em opinião quando adquire um caráter verbal e simbólico". " Muitas são as definições para o termo opinião pública, dentre as principais destaco:

$\checkmark$ a opinião pública pode ter ou não um caráter político;

$\checkmark$ é mais que a pura e simples soma das opiniões, pois resulta de uma elaboração maior;

$\checkmark$ é influenciada pelos veículos de comunicação massiva;

$\checkmark$ poderá ou não ter origem na opinião resultante da formação do público;

$\checkmark$ não deve ser confundida com a vontade popular.

Monique Augras explica que a opinião pública é, declaradamente, uma alavanca na mão do demagogo. Daí em diante aparecerá um duplo aspecto: expressão genuína da vontade do povo e meio de manipulação desse povo. Nem sempre a opinião pública influencia e determina ações. Desta maneira, é necessário repensar

3 AUGRAS, Monique. À procura do conceito de opinião pública. In: Opinião pública: teoria e processo. Petrópolis: Vozes, 1970. Cap. I, p. 11.

${ }^{4}$ DA VIÁ, Sarah Chucid. Opinião pública: técnica de formação e problemas de controle. São Paulo: Loyola, 1983, p. 50. 
quais são os fatores que interferem na formação e no desenvolvimento da opinião pública.

\section{Formação da opinião pública}

Muitos são os fatores que interferem na formação da opinião pública. Dentre eles, destaco os fatores sociais e psicológicos. A classe social e as várias relações estabelecidas interferem na formação da opinião pública, mas são os fatores psicológicos que melhor explicam a formação da opinião pública. Para a Psicologia, opinião é a disposição para expressar-se. Assim sendo, a opinião é de natureza comunicativa e interpessoal. Serve de mediadora entre o mundo exterior e a pessoa sob dois aspectos: 1) adaptação à realidade e ao grupo; 2) exteriorização", como explica Sarah C. da Viá.

Ocorre que a adaptação à realidade e ao grupo, bem como a exteriorização, envolvem a identificação, pois todos desejam a aprovação social. Ainda considerando a identificação, iremos encontrar os estereótipos criados nas sociedades de massa, onde os fatores afetivos e irracionais funcionam com maior intensidade. Os estereótipos apresentam algumas características que auxiliam sobremaneira a formação e desenvolvimento da opinião pública:

$\checkmark$ o estereótipo é persistente, pode permanecer por gerações;

$\checkmark$ é elaborado por um grupo para definir-se ou definir outro grupo;

$\checkmark$ apresenta uma imagem idealizada do próprio grupo;

$\checkmark$ tem função compensatória de frustrações, assim, o outro grupo passa a ser responsabilizado pelas frustrações. 
Criar estereótipos, alterar e induzir opiniões irá requerer persuasão. Esta, por sua vez, tem na propaganda sua melhor arma de ação, pois a propaganda pode ser definida como técnica que manipula as representações, os estereótipos e influencia nas ações humanas, nas atitudes das pessoas. Por outro lado, sabemos que o homem é um ser social, passível de influência e, portanto, pode ser persuadido. Quer e deseja a aprovação social. A propaganda é considerada suspeita, porque na área da discussão pública, molda opiniões e julgamentos, não baseada apenas no mérito da controvérsia, mas, principalmente, agindo sobre os sentimentos. "O objetivo precípuo da propaganda é implantar uma atitude que vem a ser sentida pelas pessoas como natural, certa e espontânea. Deseja assim a propaganda criar uma convicção e obter ação de acordo com essa convicção". 5

\section{Público e opinião pública}

Ao se falar em opinião pública, muitos têm em mente que este é um fenômeno, um processo no qual acontece a formação de um consenso. "A culminância desses estudos coincide aqui com o tratamento de opinião pública como sendo um processo intelectual, iniciado com o surgimento de questões de interesse comum, submetidas aos diferentes pontos de vista, seguidas pela deflagração da controvérsia, derivando esta em soluções alternativas, cuja opção sugere o acordo" 6. Parte-se da definição de público como sendo um público organizado que detém informações sobre o mesmo assunto. Mas, na verdade, não é assim que ocorre este processo.

Opinião pública não é a soma das opiniões do público em geral, muito menos a confluências das mesmas. Não se elabora, no plano coletivo, um consenso, não se forma uma única opinião. O que temos são vários públicos, que dispõem de opiniões e até mesmo

${ }^{5}$ ANDRADE, Cândido Teobaldo de Souza. Público e opinião pública. In: Curso de relações públicas. São Paulo: Atlas, 1980, p. 15.

${ }^{6}$ CORREA, T. G. Contato imediato com a opinião pública: bastidores da ação política. São Paulo: Global, 1988, p. 43. 
informações diferenciadas para o mesmo fato. Estes públicos diversos não chegam em um acordo. $\mathrm{O}$ que acontece é que estes tentam disseminar suas opiniões por meio da mídia. É certo que nem todos os grupos ou públicos possuem a mesma visibilidade midiática, mas são aqueles que conseguem tornar pública uma determinada opinião que saem ganhando. É uma espécie de "acordo forjado". Ou seja, opinião pública nada mais é do que a opinião de um determinado grupo. Em razão das influências dos grupos que formam a opinião dominante, o seu caráter público significa, na verdade, a expressão desta dominância e não a discussão descompromissada de temas com vistas a extrair a melhor posição. Por tudo isso, a opinião pública funciona como uma expressão estratégica e fundamentalmente voltada muito mais a encobrir - interesses particularistas e privados - do que a revelar. Em outras palavras, a mídia movimenta-se e nutre-se desse ambiente indefinido constituído pelo interesse e pela opinião privados, mas que se manifestam como públicos. ${ }^{7}$

O que acaba por formar-se, então, nada mais é do que a opinião do público ao invés de uma opinião pública. Corrêa define opinião pública como sendo uma opinião autorizada, ou qualificada; enquanto faz entender que a existência de uma opinião do público seja apenas uma popularização da opinião. Cândido Teobaldo de Souza Andrade caracteriza a opinião pública como sendo:

$\checkmark$ uma opinião composta, formada das diversas opiniões existentes no público;

$\checkmark$ normalmente diferente da opinião de qualquer elemento do público;

$\checkmark$ não é, necessariamente, a opinião da maioria;

${ }^{7}$ FONSECA, F. C. P. Divulgadores e vulgarizadores: a grande imprensa e a constituição da hegemonia ultraliberal no Brasil. Tese (Doutorado em História). São Paulo: Universidade de São Paulo, 2000, p. 19. 
$\checkmark$ não é uma opinião unânime;

$\checkmark$ está em contínuo processo de formação das diversas opiniões existentes no público;

$\checkmark$ está em contínuo processo de formação e em direção a um consenso completo, sem nunca alcançá-lo.

Sabe-se que os grupos de interesse, as pessoas interessadas e os espectadores constituem o público. Os grupos de interesse têm importante papel na formação da opinião pública, pois "colocam a controvérsia e esforçam-se para obter aliados entre os desinteressados". ${ }^{8}$ Desta forma, o desinteresse e a não informação contribuem para a ação dos grupos de interesse. "Esses grupos de interesse, no seu esforço para moldar opiniões, podem provocar, pela propaganda, o estabelecimento de atitudes emocionais e sentimentos. A contrapropaganda faz aparecer, novamente, a controvérsia e o processo de discussão. Assim, pode-se notar que a propaganda é prejudicial somente quando existe apenas uma propaganda".

De fato, a opinião pública deve funcionar como fiscal necessário e, para que isto ocorra, os seres racionais devem tornar-se cada vez mais racionais, mas vivemos em uma sociedade de massas onde o interesse privado geralmente se sobrepõe ao interesse público. Hoje, o que temos é a multidão, que foi característica da Antiguidade e da Idade Média. Temos a massa de consumidores. Onde está o público?

A opinião pública não é resultado do impulso de multidões passageiras que, excitadas por um fato novo e na fantasia criada pelos estereótipos e apaixonada por seus oradores, precisam adquirir a exata consciência de nação. Precisamos não só informar, mas

${ }^{8}$ ANDRADE, Cândido Teobaldo de Souza. Público e opinião pública. In: Curso de relações públicas. São Paulo: Atlas, 1980, p. 17.

${ }^{9}$ ANDRADE, Cândido Teobaldo de Souza. Público e opinião pública. In: Curso de relações públicas. São Paulo: Atlas, 1980, p. 19. 
principalmente formar. Canfield já registrava: "No seu papel de divulgar informações ao público, o profissional de Relações Públicas ocupa uma posição chave na formação de uma opinião pública esclarecida".

Stuart Mill e Tocqueville também falam sobre a opinião pública. Eles explicam que ela continua sendo utilizada no debate público contemporâneo, sobretudo na grande imprensa escrita ao colocar-se como sua representante. Este é um falso conceito, porque, primeiramente, existem inúmeras explicações conceituais, o que faz deste conceito um verdadeiro campo minado, tal a divergência quanto às suas premissas.

Mill escreve ainda que a opinião pública para os grandes jornais significa a opinião de seus leitores, ou seja, nada mais do que 15 milhões de leitores num universo de 170 milhões de habitantes. Esta opinião, embora privada, tende-se a passar por pública. "Opinião pública deveria expressar movimento e dinamismo, e não a cristalização de uma certa opinião. A mídia movimenta-se e nutre-se deste ambiente indefinido constituído pelo interesse e pela opinião privados que passam a manifestar-se como públicos".

Mccombs e Shaw explicam que a mídia pauta a sociedade, definindo o deve ser discutido. É o fenômeno do agenda setting.

Em conseqüência da ação dos jornais, da televisão e dos outros meios de informação, o público sabe ou ignora, presta a tenção ou descura, realça ou negligencia elementos específicos dos cenários públicos. As pessoas têm tendência para incluir ou excluir dos seus próprios conhecimentos aquilo que os mass media incluem ou excluem do seu próprio conteúdo. Além disso, o público tende a atribuir àquilo que esse conteúdo inclui uma

${ }^{10}$ CANFIELD, Bertrand R. Opinião pública. In: Relações públicas: princípios e problemas. São Paulo: Pioneira, 1961. Vol.1. p. 30.

${ }_{11}^{11}$ MILL, J. S. Sobre a liberdade. Petrópolis: Vozes, 1991.

12 FONSECA, F. C. P. Divulgadores e vulgarizadores: a grande imprensa e a constituição da hegemonia ultraliberal no Brasil. São Paulo. Tese (Doutorado em História). São Paulo: Universidade de São Paulo, 2000, p. 19. 2000 
mesma importância que reflete de perto a ênfase atribuída pelos mass media aos acontecimentos, aos problemas, às pessoas. ${ }^{13}$

Esse conceito é complementado pela hipótese do enquadramento. De acordo com estes autores, a mídia fornece certos esquemas narrativos, segundo os quais torna-se possível interpretar os acontecimentos. $\mathrm{Na}$ verdade, privilegia-se alguns esquemas em detrimentos a outros, ou algumas opiniões em detrimento a outras. $\mathrm{O}$ controle sobre a agenda e sobre a visibilidade dos diversos enquadramentos, que alicerça a centralidade dos meios de comunicação.

\section{Conclusão}

Devido às influências dos grupos que formam a "opinião pública", o caráter público deste significa, na verdade, a expressão de uma dominância e não a discussão descompromissada e aberta sobre os temas, objetivando chegar a uma conclusão comum. A opinião pública, desta maneira, volta-se mais a encobrir interesses privados do que a esclarecer.

\section{BIBLIOGRAFIA}

AUGRAS, Monique. À procura do conceito de opinião pública. In: Opinião pública: teoria e processo. Petrópolis: Vozes. 1970. Cap I, p.11-19.

ANDRADE, Cândido Teobaldo de Souza. Público e opinião pública. In: Curso de relações públicas. São Paulo: Atlas, 1980. p.15-20.

CANFIELD, Bertrand R. Opinião pública. In: Relações públicas: princípios e problemas. São Paulo: Pioneira, 1961. Vol.1, p.27-48.

13 SHAW, E. Agenda-Setting and Mass Communication Theory. Gazette International Journal for Mass Communication Studies, v. 25, n. 2, 1979, p. 96. 
CHILDS, Harwood L. Opinião pública e controle social. In: Relações públicas, propaganda e opinião pública. Rio de Janeiro, FGV, 1976. p. 164-175.

CORREA, T. G. Contato imediato com a opinião pública: bastidores da ação política. São Paulo. Global. 1988.

DA VIÁ, Sarah Chucid. Opinião pública: técnica de formação e problemas de controle. São Paulo: Loyola, 1983. p. 7-58.

FONSECA, F. C. P. Divulgadores e vulgarizadores: a grande imprensa e a constituição da hegemonia ultraliberal no Brasil. São Paulo. Tese (Doutorado em História). São Paulo: Universidade de São Paulo, 2000, p. 19. 2000

MCCOMBS, M \& SHAW, D. The Agenda Setting function of Mass Media. Public Opinion Quartely, New York, 1972, v.36, n.2, p. 96187.

MILL, J. S. Sobre a liberdade. Petrópolis: Vozes, 1991.

SHAW, E. Agenda-Setting and Mass Communication Theory. Gazette - International Journal for Mass Communication Studies, v. 25, n. 2, 1979.

TOCQUEVILlE, A. Da democracia na América. São Paulo: Nacional, 1969. 